\title{
Targeting focal adhesion kinase overcomes erlotinib resistance in smoke induced lung cancer by altering phosphorylation of epidermal growth factor receptor
}

\author{
Hitendra S. Solanki ${ }^{1,2, *}$, Remya Raja ${ }^{1, *}$, Alex Zhavoronkov ${ }^{3}$, Ivan V. Ozerov ${ }^{3}$, Artem \\ V. Artemov ${ }^{3}$, Jayshree Advani ${ }^{1,4}$, Aneesha Radhakrishnan ${ }^{1}$, Niraj Babu ${ }^{1,4}$, Vinuth \\ N. Puttamallesh ${ }^{1,5}$, Nazia Syed ${ }^{1}$, Vishalakshi Nanjappa ${ }^{1}$, Tejaswini Subbannayya ${ }^{1}$, \\ Nandini A. Sahasrabuddhe ${ }^{1}$, Arun H. Patil ${ }^{1,2,6}$, T.S. Keshava Prasad ${ }^{1,6,7}$, Daria

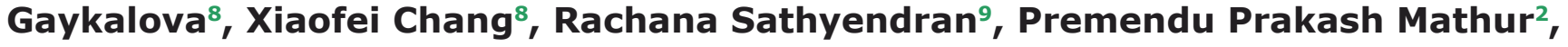 \\ Annapoorni Rangarajan ${ }^{9}$, David Sidransky ${ }^{8}$, Akhilesh Pandey ${ }^{10,11,12,13}$, Evgeny \\ Izumchenko ${ }^{8}$, Harsha Gowda ${ }^{1,6}$ and Aditi Chatterjee ${ }^{1,6}$ \\ ${ }^{1}$ Institute of Bioinformatics, International Tech Park, Bangalore 560066, India \\ ${ }^{2}$ School of Biotechnology, Kalinga Institute of Industrial Technology, Bhubaneswar, Odisha 751024, India \\ ${ }^{3}$ Insilico Medicine, Inc., Emerging Technology Centers, Johns Hopkins University at Eastern, Baltimore, MD 21218, USA \\ ${ }^{4}$ Manipal Academy of Higher Education, Manipal, Karnataka 576104, India \\ ${ }^{5}$ School of Biotechnology, Amrita University, Kollam 690525, India \\ ${ }^{6}$ Center for Systems Biology and Molecular Medicine, Yenepoya (Deemed to be University), Mangalore 575018, India \\ 7 NIMHANS-IOB Proteomics and Bioinformatics Laboratory, Neurobiology Research Centre, National Institute of Mental \\ Health and Neurosciences, Bangalore 560029, India \\ 8 Department of Otolaryngology-Head and Neck Surgery, Johns Hopkins University School of Medicine, Baltimore, MD \\ 21231, USA \\ ${ }^{9}$ Department of Molecular Reproduction, Development and Genetics, Indian Institute of Science, Bangalore, 560012, India \\ ${ }^{10}$ McKusick-Nathans Institute of Genetic Medicine, Johns Hopkins University School of Medicine, Baltimore, MD 21205, USA \\ 11 Department of Biological Chemistry, Johns Hopkins University School of Medicine, Baltimore, MD 21205, USA \\ 12 Department of Oncology, Johns Hopkins University School of Medicine, Baltimore, MD 21205, USA \\ ${ }^{13}$ Department of Pathology, Johns Hopkins University School of Medicine, Baltimore, MD 21205, USA \\ * These authors contributed equally to the manuscript \\ Correspondence to: Aditi Chatterjee or Harsha Gowda, email:aditi@ibioinformatics.org or harsha@ibioinformatics.org \\ Keywords: cigarette smoke; epidermal growth factor receptor; NSCLC; phosphoproteomics; drug resistance \\ Received: July 29,2017 Accepted: December 15, $2017 \quad$ Published: February 23, 2018
}

Copyright: Solanki et al. This is an open-access article distributed under the terms of the Creative Commons Attribution License 3.0 (CC BY 3.0), which permits unrestricted use, distribution, and reproduction in any medium, provided the original author and source are credited.

ABSTRACT

EGFR-based targeted therapies have shown limited success in smokers. Identification of alternate signaling mechanism(s) leading to TKI resistance in smokers is critically important. We observed increased resistance to erlotinib in H358 NSCLC (non-small cell lung carcinoma) cells chronically exposed to cigarette smoke (H358-S) compared to parental cells. SILAC-based mass-spectrometry approach was used to study altered signaling in H358-S cell line. Importantly, among the top phosphosites in H358-S cells we observed hyperphosphorylation of EGFR (Y1197) and non-receptor tyrosine kinase FAK (Y576/577). Supporting these observations, a transcriptomic-based pathway activation analysis of TCGA NSCLC datasets revealed that FAK and EGFR internalization pathways were significantly upregulated in smoking patients, compared to the never-smokers and were associated with elevated PI3K signaling and lower level of caspase cascade and E-cadherin pathways activation. 


\section{We show that inhibition of FAK led to decreased cellular proliferation and invasive ability of the smoke-exposed cells, and restored their dependency on EGFR signaling. Our data suggests that activation of focal adhesion pathway significantly contributes to erlotinib resistance, and that FAK is a potential therapeutic target for management of erlotinib resistance in smoke-induced NSCLC.}

\section{INTRODUCTION}

Smoking is the leading cause of lung cancer, which attributes to $87 \%$ of lung cancer deaths in males and $70 \%$ of lung cancer deaths in females in the United States (Cancer Facts \& Figures 2014). Non-small cell lung carcinoma (NSCLC) accounts for $85 \%$ of lung cancer cases, which is diagnosed primarily in current or former smokers [1]. NSCLC is usually diagnosed at an advanced stage owing to the late onset of clinical symptoms and inadequate screening programs. It is established that tyrosine kinases serve as excellent therapeutic targets [2]. Currently, the first line of treatment for NSCLC are EGFR inhibitors (erlotinib, gefitinib) which are known to benefit patients harboring specific activating somatic mutations (exon 19 deletion or exon 21 substitution (L585R) or exon 18 substitution (G719C, G719S, G719A)) in the kinase domain of EGFR [3]. Acquired drug resistance eventually arises in most, if not all, treated patients [4] and secondary mutations in EGFR (T790M), c-met or Her2 amplification are known to be associated with acquired drug resistance [5]. Among the NSCLC patients harboring EGFR mutations who underwent tyrosine kinase inhibitor (TKI) treatment, non-smokers have shown longer progression free survival response than ever smokers $[6,7]$. Several in vitro studies have shown that acute exposure to cigarette smoke mediates development of lung cancer and resistance to TKIs in NSCLC in both wild type (WT) EGFR and TKI sensitive mutants [8-11]. However, underlying mechanism(s) leading to erlotinib resistance upon cigarette smoke exposure in NSCLC is not well understood. This preempts the need to investigate the underlying signaling pathways contributing to resistance to EGFR-targeted TKIs in NSCLC.

Mass spectrometry based-phosphoproteome profiling is widely used to identify alterations in signaling and to identify novel therapeutic targets in cancer [1214]. We have shown previously that chronic exposure to cigarette smoke induces distinct molecular signatures in lung cancer cell line exposed to cigarette smoke [15]. In this study, we show that chronic exposure to cigarette smoke renders resistant to erlotinib in lung cancer cells. We carried out SILAC-based quantitative mass spectrometry analysis to identify aberrantly activated signaling pathways in lung cancer cells chronically exposed to cigarette smoke. We identified 238 phosphosites (or phosphopeptides) corresponding to 157 proteins of which 111 phosphosites were hyperphosphorylated while 66 were hypophosphorylated (2.0 -fold) in H358-S cells compared to parental cells. We observed hyperphosphorylation of key signaling molecules including EGFR (Y1197) (corresponds to the Y1173 of mature EGFR), focal adhesion kinase 1 (FAK or PTK2) (Y576/577) and Fyn related Src family tyrosine kinase (FRK or RAK) (Y46) amongst others. We identified differential phosphorylation status of EGFR in H358-S cells which directly correlated with erlotinib resistance. Using iPANDA, a bioinformatics software suite for qualitative analysis of intracellular signaling pathway activation based on transcriptomic data $[16,17]$, we revealed that FAK signaling and EGFR internalization pathway were significantly upregulated in smoking patients from TCGA NSCLC dataset, compared to the never-smoker counterparts. We further report that FAK signaling regulates EGFR phosphorylation in H358 smoke exposed cells and NSCLC cells derived from smokers independent of SRC. Our study underscores the importance of FAK pathway in regulating EGFR activity in NSCLC and could be an effective therapeutic strategy for NSCLC patients with smoking habits.

\section{RESULTS}

\section{Chronic exposure to cigarette smoke enhanced tumorigenicity and erlotinib resistance in NSCLC}

In our earlier studies we have shown that chronic exposure to smoke increased the proliferative and invasive abilities of lung cancer H358 cells [15]. The untreated cells and smoke-exposed cells were designated as H358-P and H358-S, respectively. In this study, we further reaffirmed the enhanced tumorigenic capacity of H358-S cells using an in vivo mice model. Xenograft studies indicated that mice bearing H358-S tumors showed increased growth kinetics compared to H358-P group (Figure 1A-C). H358 cells have been reported to be sensitive to erlotinib [18]. We next determined the chronic effects of cigarette smoke exposure to erlotinib sensitivity of H358-S and other NSCLC cells derived from smokers (H1299 (WT-EGFR) and H1650 (Exon 19 deletion)). As shown in Figure 1D, the $\mathrm{H} 358-\mathrm{S}$ cells acquired resistance to erlotinib $\left(\mathrm{IC}_{50}>\right.$ 


\section{Figure 1}

A



B

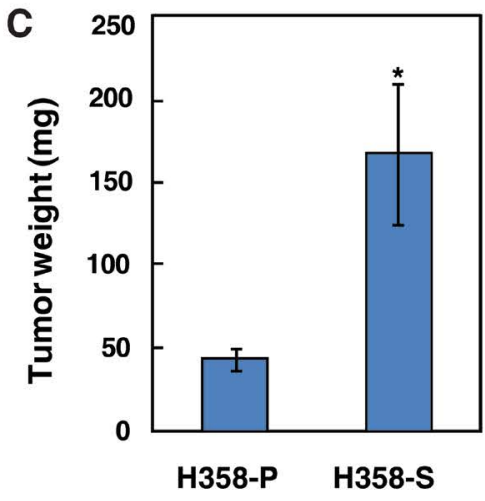

D

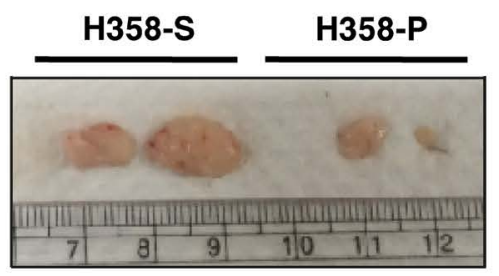

E
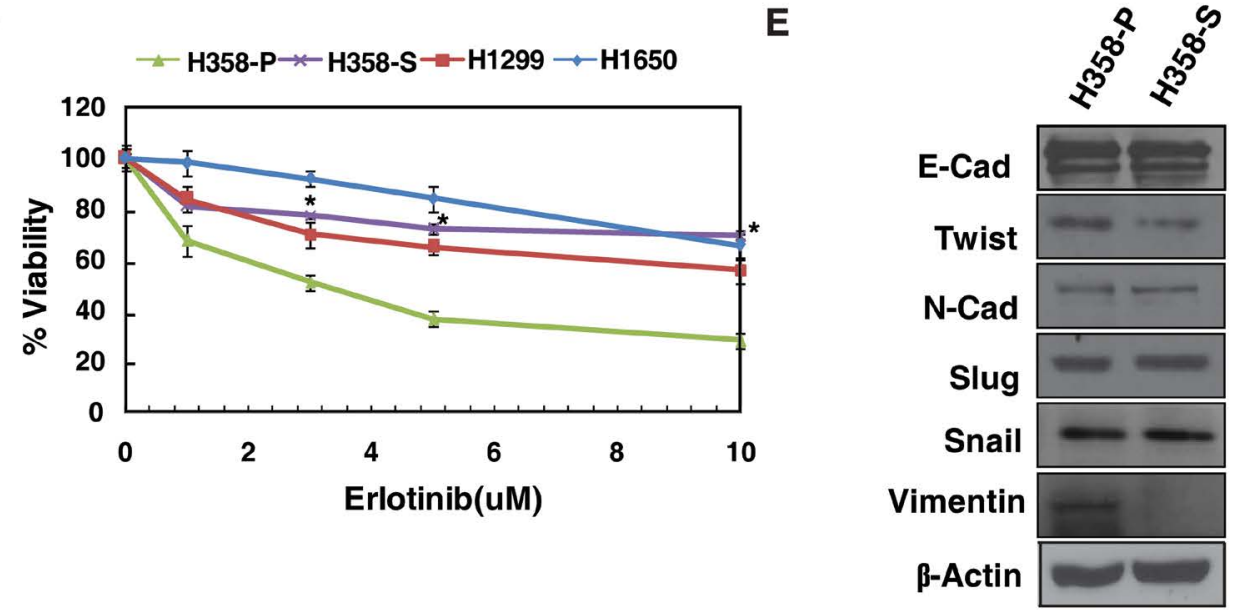

Figure 1: Chronic exposure to cigarette smoke enhanced tumorigenicity and erlotinib resistance in NSCLC. (A) H358-P and H358-S $\left(2 \times 10^{6}\right)$ cells were injected subcutaneously into the flanks of male NOD-SCID mice. The growth kinetics over a period of 3 weeks has been plotted. Representative pictures (B) and bar graph representing the tumor weights (C) are shown. (D) Cellular sensitivity of H358-P, H358-S, H1299 and H1650 cells treated with indicated concentrations of erlotinib. Experiments were performed in triplicates. *p $<0.05$. (E) Western blot analysis of epithelial and mesenchymal markers in H358-P and H358-S cells. $\beta$-actin served as a loading control. 
$10 \mu \mathrm{M})$ compared to H358-P. The acquired resistance of H358-S cells were at par with, H1299 and H1650 NSCLC cell lines which are known to be resistant to erlotinib $\left(\mathrm{IC}_{50}\right.$ $>10 \mu \mathrm{M})$.

\section{Chronic cigarette smoke exposure does not induce epithelial-mesenchymal transition in $\mathbf{H 3 5 8 - S}$ cells}

Previous studies have shown that acute exposure to cigarette smoke induces epithelial to mesenchymal transition (EMT) transition in lung epithelial cells [19]. In addition, studies have shown a close link between cigarette smoke induced EMT and acquired resistance to EGFR-TKI in NSCLC [20]. To confirm whether chronic exposure to smoke induce EMT in H358-S cells, we checked the expression of epithelial and mesenchymal markers in H358-P and H358-S cells. As shown in Figure $1 \mathrm{E}, \mathrm{E}$-cadherin expression remained unchanged and we observed a decrease in expression of vimentin between H358-P and H358-S cells. Other mesenchymal markers remained unchanged between H358-P and H358-S cells. Studies in hepatocellular carcinoma and ovarian carcinoma indicate enhanced migratory and invasive properties of cells independent of EMT [21, 22]. Our data also indicates that the increased resistance to erlotinib in $\mathrm{H} 358-\mathrm{S}$ cells is independent of EMT transition, suggesting the existence of alternative mechanism(s) for erlotinib resistance in lung cancer cells upon chronic exposure to cigarette smoke.

\section{Chronic exposure to cigarette smoke induces altered signaling in lung cells}

Acquired resistance to EGFR-TKI therapy has been reported in both WT-EGFR and EGFR sensitive mutants subgroup among smokers [6, 8]. Moreover, TKI-responsive patients often develop resistance to these drugs if they resume smoking post-treatment [23]. Studies also indicate that smokers acquire distinct EGFR mutations [24] and that exposure to smoke leads to aberrant phosphorylation of EGFR that confers TKIresistance in smokers [25]. Consistently, our results show that $\mathrm{H} 358$ cells acquired resistance to erlotinib after chronic exposure to cigarette smoke. We carried out SILAC-based quantitative proteomic approach to systematically interrogate altered signaling pathways that could potentially contribute to erlotinib resistance in H358-S cells. The workflow for phosphotyrosine analysis is depicted in Supplementary Figure 1. Mass spectrometry based analysis led to the identification of 238 phosphosites corresponding to 157 proteins of which 111 phosphosites were hyperphosphorylated and 66 were hypophosphorylated ( $\geq 2$-fold) in H358-S cells.
The partial list of hyperphosphorylated sites is shown in Table 1. The complete list of identified phosphopeptides is provided in Supplementary Table 1.

We identified hyperphosphorylation of receptor tyrosine kinases including EGFR at Y1197 (2.6-fold) and ephrin type-A receptor 1 (EPHA1) at Y781 (10.8fold). Phosphorylation of EGFR at Y1197 leads to internalization of the receptor $[26,27]$. The ephrin receptor is up-regulated in many cancer types including NSCLC, specifically in smokers [28-30]. In addition, we also observed hyperphosphorylation of non-receptor tyrosine kinases including PTK2/FAK and FRK/RAK at Y576/577 (3.1-fold) and Y46 (2.1-fold), respectively. Further, our data indicates hyperphosphorylation of several key members of SRC and FAK signaling cascade including paxillin (PXN) (2.8-fold), WASL (2.5-fold), CTTN (2.1-fold), CAV1 (2.0-fold) and Talin-1 (TLN1) (3.5fold). These findings suggest widespread perturbation of tyrosine phosphorylation-regulated signaling in response to cigarette smoke in lung cancer cells. The MS and MS/ MS spectra of hyperphosphorylated phosphopeptides of FAK (Y576/577) and EGFR (Y1197) are depicted in Figure 2 (A-B); MS and MS/MS spectra for FRK (Y46) is depicted in Supplementary Figure 2.

\section{Cigarette smoke induces aberrant EGFR phosphorylation in $\mathbf{H 3 5 8}$ lung cancer cells}

Studies have reported that acute exposure of cigarette smoke induced altered phosphorylation of EGFR in lung cells [25]. We determined the phosphorylation status of EGFR at Y1197 in H358-S cell line. In concordance with our mass spectrometry data, Western blot analysis confirmed hyperphosphorylation of EGFR at its autophosphorylation site Y1197 in H358-S cells (Figure 2C). Phosphorylation at Y1197 is known to contribute to EGFR internalization [26, 27]. The phosphorylated form of EGFR, specifically at Y1068 is reported to be predictive marker to screen TKI-responsive population in NSCLC with wild-type EGFR [31]. Gowda et al., have shown that phosphorylation of EGFR at Y1068 can be a predictive marker of erlotinib sensitivity and used to screen TKIs sensitive pancreatic cancer patients [32]. Though we did not identify EGFR Y1068 in our mass spectrometry data, we determined the phosphorylation status of EGFR at Y1068 in H358-S cells. In concordance with previous published studies, we observed a loss of phosphorylation of EGFR at Y1068 in erlotinib resistant H358-S cells compared to the parental cells (Figure 2C). We also observed increased phosphorylation of SRC (Y416) and FAK (Y576/577) in H358-S cells. SRC is known to be phosphorylated and activated upon acute exposure of cigarette smoke or when treated with NNK-(Nitrosamine 4-(methylnitrosamino)-1-(3-pyridyl)-1-butanone), an 
Table 1: Partial list of hyperphosphorylated proteins upon cigarette smoke exposure in $\mathrm{H358}$ cells

\begin{tabular}{|l|l|l|l|l|l|}
\hline & Protein & $\begin{array}{l}\text { Gene } \\
\text { Symbol }\end{array}$ & Phosphopeptide & Site & $\begin{array}{l}\text { CSC/ } \\
\text { parental } \\
\text { fold } \\
\text { change) }\end{array}$ \\
\hline 1. & $\begin{array}{l}\text { Mitogen-activated } \\
\text { protein kinase 14 }\end{array}$ & MAPK14 & HTDDEMTG[Y]VATR & 6.8 \\
\hline 2. & $\begin{array}{l}\text { Mitogen-activated } \\
\text { protein kinase 3 }\end{array}$ & MAPK3 & IADPEHDHTGFLTE[Y]VATR & Y204 & 3.2 \\
\hline 3. & Paxillin & PXN & VGEEEHV[Y]SFPNKQK & Y118 & 2.8 \\
\hline 4. & Focal adhesion kinase 1 & PTK2 & YMEDST[Y]YKASK & Y576 & 3.1 \\
\hline 5. & $\begin{array}{l}\text { Epidermal growth } \\
\text { factor receptor }\end{array}$ & EGFR & EAKPNGIFKGSTAENAE[Y]LR & Y1197 & 2.6 \\
\hline 6. & $\begin{array}{l}\text { Wiskott-Aldrich } \\
\text { syndrome-like }\end{array}$ & WASL & DRETSKVI[Y]DFIEK & Y256 & 2.5 \\
\hline 7. & Cortactin & CTTN & GPVSGTEPEPVYSMEAAD[Y]R & Y453 & 2.1 \\
\hline
\end{tabular}

important carcinogen present in cigarette smoke [8, 25]. Also, SRC plays a key role in phosphorylation of FAK at Y576 and Y577, leading to its activation [33, 34]. In addition, we identified hyperphosphorylation of FRK/ RAK (Y46) (2.1-fold) in H358-S cells. FRK/RAK belongs to Src family of kinases and is reported to phosphorylate EGFR at Y1197, resulting in receptor internalization [35]. Due to unavailability of specific phospho-antibody against FRK, we studied the expression levels of FRK and our data shows increased expression of FRK in the H358-S cells. Overexpression and hyperphosphorylation of FRK is reported in many cancer types, including lung cancer $[35,36]$. Our findings indicate an altered phosphorylation state of EGFR with concomitant activation of SRC/FAK signaling in erlotinib-resistant H358-S cells. In agreement with the in vitro data, H358-S xenograft tissue also showed increased phosphorylation of EGFR at Y1197 and a decreased phosphorylation at Y1068. Similarly, we observed hyperphosphorylation of SRC, FAK and an increased expression of FRK in the H358-S xenograft tissue compared to H358-P tumors (Figure 2D). Taken together, our data strongly suggests that treatment with cigarette smoke results in aberrant phosphorylation of EGFR with concomitant activation of SRC/FAK signaling and could be one of the factors contributing to erlotinib resistance.

\section{Cigarette smoke exposure correlates with upregulation of FAK signaling pathway}

We first performed pathways enrichment analyses with either Search Tool for Interactions of Chemicals (STITCH) and Ingenuity Pathway Analysis (IPA) bioinformatic toolsets, using the differentially regulated kinases (from the phospho proteomic data) in H358-S cells as an input. Interestingly, analysis with STITCH revealed that focal adhesion pathway was among the top 5 signaling axes enriched in H358-S cells (Supplementary Table 2A). In addition, IPA revealed the enrichment of integrin and paxillin signaling cascade, where the activation of focal adhesion kinase is critically important (the list of top 5 canonical signaling cascades identified in IPA analysis is provided in Supplementary Table 2B). Although the direct comparison of the enrichment analyses generated by different approaches should be addressed with caution, this data further supports our observation that chronic exposure to cigarette smoke may activate the focal adhesion pathways to support proliferation and survival.

We next used iPANDA, a bioinformatics software suite for qualitative analysis of intracellular signaling pathway activation based on transcriptomic data [16, 17], to assess the level of FAK pathway activation in current smokers $(\mathrm{n}=239)$ or never-smoker $(\mathrm{n}=91)$ patients 
A

\section{Focal adhesion kinsae (FAK/PTK2) YMEDSTPYYKASK}

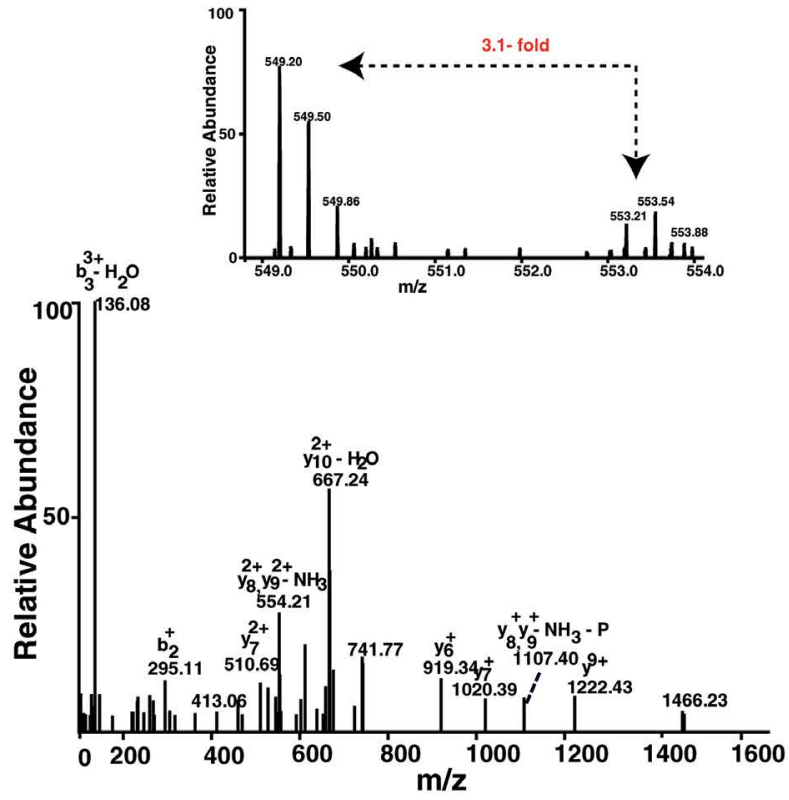

C

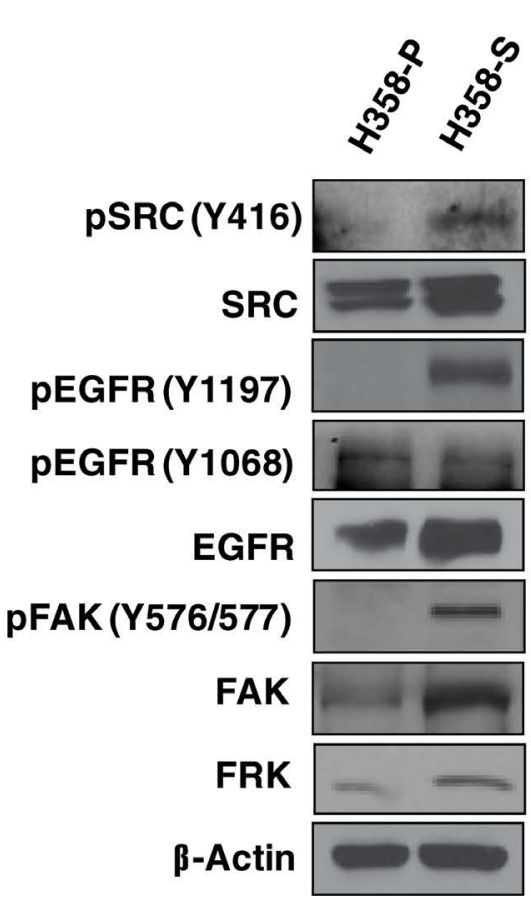

\section{Epidermal growth factor receptor(EGFR) EAKPNGIFKGSTAENAEpYLR}



D
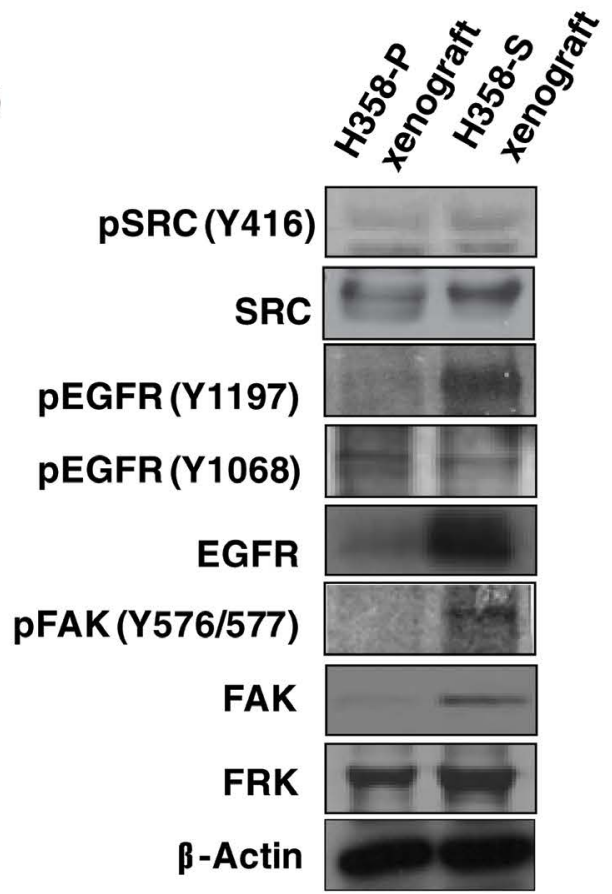

Figure 2: Representative MS and MS/MS spectra of hyperphosphorylated peptide of in H358 smoke-exposed cells. (A) Focal adhesion kinase (Y576/577) (B) Epidermal growth factor receptor (Y1197) (C) Western blot analysis of p-SRC, p-EGFR, p-FAK and FRK in H358-P and H358-S cells (D) Western blot analysis of p-SRC, p-EGFR, p-FAK and FRK between H358-S xenograft tissue and H358-P xenograft tissue. 
with NSCLC (both adenocarcinoma and squamous cell carcinoma) derived from The Cancer Genome Atlas database. The transcriptomic data from noncancerous lung samples of never-smoking individuals $(n=7)$ was used as a reference. Signaling events mediated by focal adhesion kinase were derived from the Pathway Interaction Database (PID) curated by NCI/Nature. Consistent with our cell line results, main FAK pathway activation was significantly upregulated in smoking patients compared to the never smokers (Figure 3A, 3B). In various solid malignancies including lung, FAK activation induces survival, migration and invasion signaling by promoting E-cadherin delocalization [37-39], upregulation of PI3K/ AKT signaling [40, 41] and suppression of apoptosis [42]. Analysis of these signaling axes retrieved from the PID collection revealed that PI3K/AKT pathway was significantly upregulated in the current smoker cohort, whereas E cadherin signaling and caspase cascade apoptosis pathway were downregulated in this group of patients compared to the never-smokers (Figure 3A, 3B). Since cigarette smoke induced EGFR phosphorylation at Y1197 (Figure 2B-D) is associated with elevated EGFR internalization rate [43, 44], decreased sensitivity to EGFR inhibitors [45, 46] and shorter progressionfree survival [47], we also assessed the levels of the EGFR internalization pathway activation in the same patient's cohorts. Notably, activation of the main EGFR internalization pathway was significantly higher in smoking patients compared to the never-smoking counterparts (Figure 3). These observations further emphasize the important role of cigarette smoke induced dysregulation of FAK signaling in lung tumorigenesis and resistance to EGFR targeted therapies.

\section{Inhibition of FAK and SRC decreases the invasive property of lung cancer cells}

Since both FAK and SRC were found to be activated in lung cancer cells chronically exposed to cigarette smoke, we assessed the potential role of FAK and $\mathrm{SRC}$ in regulating invasive potential in $\mathrm{H} 358-\mathrm{S}$ and a panel of NSCLC cells established from smokers. We observed a significant decrease in the invasive ability of the H538-S and other smoke-exposed NSCLC cells upon FAK inhibition/silencing using PF-562271 or FAK siRNA

A.
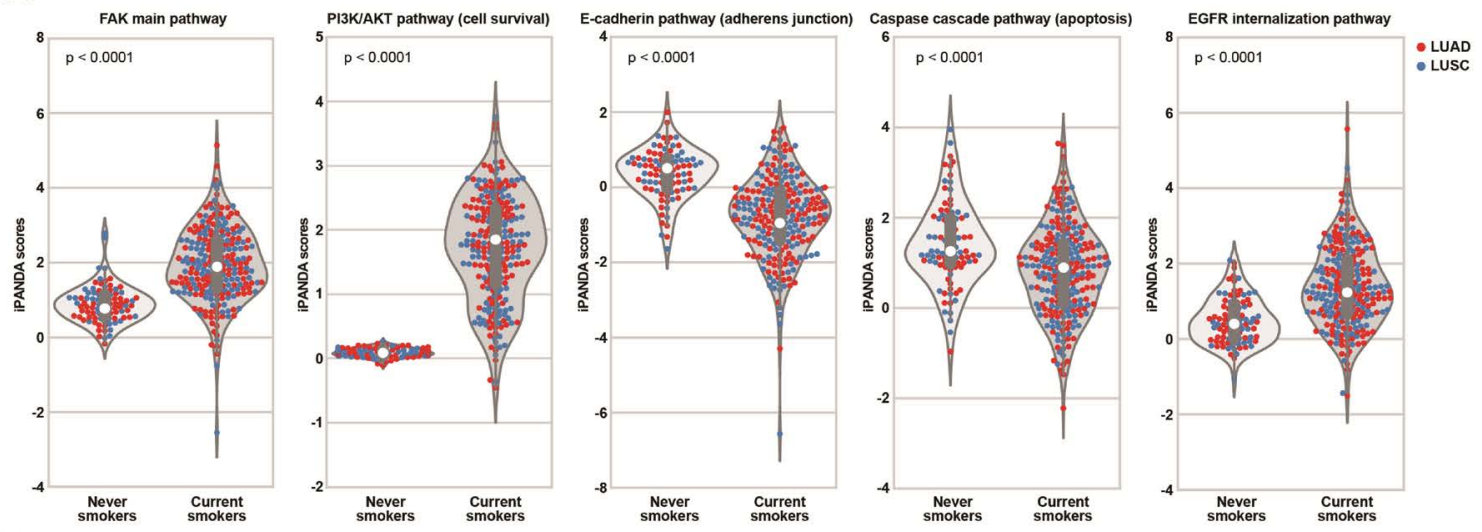

B.

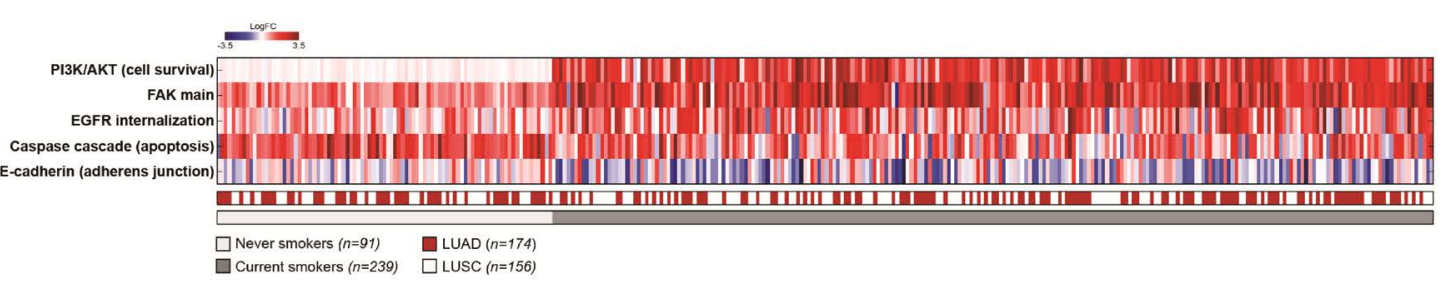

Figure 3: Cigarette smoke exposure correlates with upregulation of FAK signaling pathway in TCGA NSCLC dataset. iPANDA software suite for analysis of intracellular signaling pathway activation based on transcriptomic data was used to estimate the level of the indicated signaling pathways in never-smokers $(n=91)$ and currently smoking $(n=239)$ patients with NSCLC from TCGALUAD (lung adenocarcinoma) and TCGA-LUSC (lung squamous cell carcinoma) datasets. TCGA transcriptomic data from normal lung of never-smoking individuals was used as a reference after proper normalization. (A) Violin plots showing the differences in pathway activation scores between the never-smoker and current-smoker patients. In violin plots: red dots represent LUAD patients, blue dots represent LUSC patients, the white dot represents the median value and the gray bar is the interquartile range. (B) The heatmap of indicated differentially activated pathways in all samples analyses. Downregulated iPANDA values for each sample/pathway are indicated in blue, whilst upregulated values are shaded in red. 


\section{Figure 4}

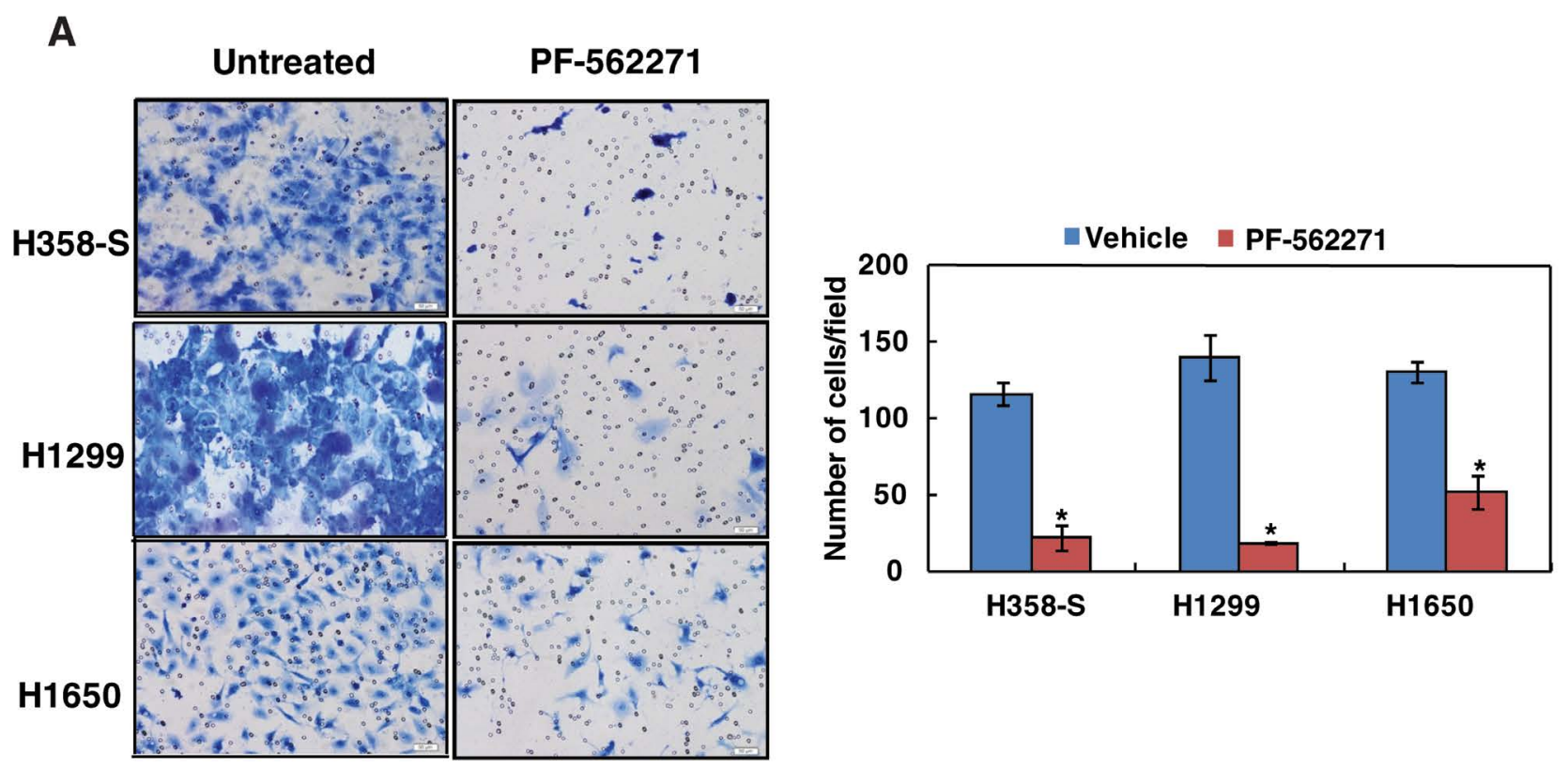

B

\section{Scrambled siRNA FAK siRNA}

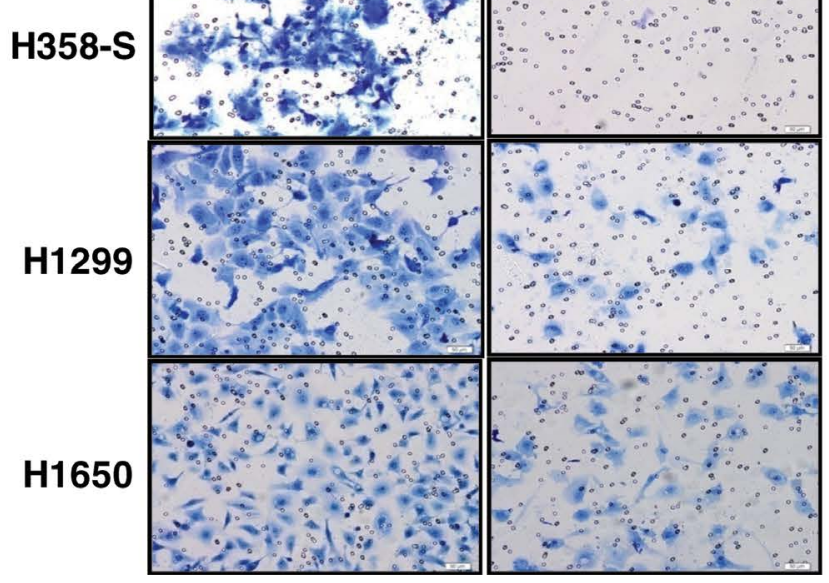

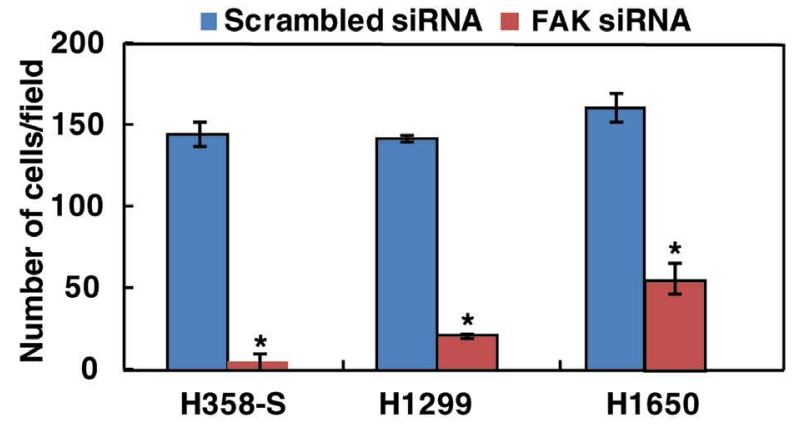

Figure 4: Inhibition of FAK decreases the invasive property of lung cancer cells. Invasion assays were carried out in a transwell system using Matrigel-coated filters and the number of cells that migrated to the lower chamber was counted. Cells that migrated are visualized following methylene blue staining in H358-S and NSCLC cell lines, H1299 and H1650 as indicated. (A) Cells were treated with either DMSO (vehicle control) or PF-562271 and invaded cells were photographed. Representative images were photographed at a magnification 10x. Invaded cells were counted and relative changes in invasive ability of H358-S and NSCLC cells upon inhibition with PF-562271 was calculated and represented graphically $\left({ }^{*} p<0.05\right)$. (B) Cells were transfected with either scrambled siRNA or FAK siRNA and invaded cells were photographed. Invaded cells were counted and relative changes in invasive ability of H358-S and NSCLC cells upon FAK silencing was calculated and represented graphically $\left({ }^{*} \mathrm{p}<0.05\right)$. Representative images were photographed at a magnification $10 \mathrm{x}$. 
(Figure 4A-B). A similar decrease in the invasive property of these cells was observed when cells were treated with SRC inhibitor dasatinib (Supplementary Figure 3A).

\section{Targeting FAK overcomes erlotinib resistance in lung cancer cells}

Having observed that the inhibition of SRC/ FAK signaling in H358-S and other NSCLC cells leads to decreased invasive ability, we sought to study the effects of these inhibitors on erlotinib sensitivity of smoke-exposed cells. In a recent study, combinatorial treatment of FAK inhibitor and erlotinib have shown synergistic effect in reducing cell viability in EGFR-TKI-resistant NSCLC cell lines [48]. H358-S, H1299 and H1650 cells were treated with varying concentration of erlotinib $(0.5 \mu \mathrm{M}, 1 \mu \mathrm{M}$ and $3 \mu \mathrm{M})$ alone or in combination with either SRC inhibitor, dasatanib $(50 \mathrm{nM})$ or FAK inhibitor, PF-562271 $(4 \mu \mathrm{M})$ (Figure 5 A-D). Combined treatment with PF-562271 (FAK inhibitor), significantly improved the sensitivity of H358-S cells to erlotinib (Figure 5A). Similarly, H1299 and $\mathrm{H} 1650$ cells also exhibited an increased sensitivity to erlotinib when treated in combination with FAK inhibitor (Figure 5B). Study by Gold et al., has reported synergistic effect of erlotinib and dasatinib in NSCLC [49] and another study has independently reported that the treatment with dasatinib can overcome cigarette smoke induced TKI resistance in NSCLC cells [8]. As FAK is a known downstream target of SRC, we next determined whether targeting SRC can have similar effect as targeting FAK. In contrast to the published results, when H358-S cells were treated with a combination of dasatinib and erlotinib, we did not observe any significant increase in the cellular response compared to the single agent therapy (Figure 5C). While the additive effect of dasatinib/ erlotinib combination on survival of H1299 and H1650 cells was significant, it was not as egregious as one seen with erlotinib/PF-562271 combination (Figure 5D). Of note, a better response to the dasatinib/erlotinib therapy seen in the H1650 cells can be attributed to the fact that H1650 cell line is known to be sensitive to dasatinib [50]. Collectively, our data indicates that inhibition of FAK with PF-562271 in combination with erlotinib can effectively reduce the cell viability of NSCLC, specifically in smokers who develops resistance to EGFR-TKI therapy.

\section{FAK inhibition alters smoke induced EGFR phosphorylation in lung cancer cells}

Our results indicate that erlotinib resistance in NSCLC can be overcome by complementing the EGFRTKI therapy with FAK inhibitors and not with SRC inhibition. Though FAK is reported to be downstream of SRC in literature, at this juncture it was unclear to us why SRC inhibition did not restore the sensitivity of the cells to erlotinib, while inhibition of FAK rendered the cells sensitive to erlotinib [37]. To understand this phenomenon, we studied the signaling mechanism in H358-S cells using FAK and SRC inhibitors, PF-562271 and dasatinib respectively. We first studied the effect of FAK inhibition on EGFR phosphorylation in $\mathrm{H} 358$-S cells. We had observed a decreased phosphorylation of EGFR at Y1068 and hyperphophorylation at EGFR Y1197 in H358-S cells compared to the parental cell-line. Upon inhibition of FAK, phosphorylation of EGFR at Y1068 was restored in H358-S cells whereas there was a loss of phosphorylation at EGFR Y1197 (Figure 6A). A similar response was also observed in the panel of smoker-derived NSCLC cell lines (H1299 and H1650). Next, we studied the effect of SRC inhibitor dasatinib on EGFR phosphorylation. SRC inhibition had little to no effect on the phosphorylation of EGFR at Y1197, and did not reinstate phosphorylation of EGFR at Y1068 (Figure 6B). Interestingly, we observed a decrease in FRK levels in presence of PF-562271 but not dasatinib (Figure 6 A-B, FRK panel); indicating that FRK might function downstream to FAK signaling in smokeexposed cells.

To understand the possible role of FRK in erlotinib resistance, we studied the effect of silencing FRK on cellular invasion. Supplementary Figure 3B shows that siRNA-mediated silencing of FRK led to decreased cellular invasion of the H358-S and other NSCLC cells. Next, we studied the effects of FRK knockdown on EGFR phosphorylation levels. We did not observe any significant change in the phosphorylation status of EGFR at both Y1197 and Y1068 upon silencing of FRK (Figure 6C). In addition, silencing of FRK in H358-S and NSCLC cells did not alter the sensitivity of cells to erlotinib (data not shown). Due to the lack of FRK phospho-antibody and specific inhibitors we could not delineate the role of FRK in mediating erlotinib resistance upon cigarette smoke exposure, and future studies are warranted to further evaluate its role in smoke-induces erlotinib resistance. Taken together our results indicate that inhibition of FAK increases/restores cellular sensitivity to erlotinib by activating EGFR, which is independent of SRC.

\section{DISCUSSION}

TKIs (erlotinib, gefitinib and afatinib) are in clinical practice to treat patients harboring specific activating somatic mutations in EGFR (exon 19 deletion or exon 21 substitution (L585R) or exon 18 substitutions (G719C, G719S, G719A) [51]. However, patients with WT-EGFR have shown poor response to TKIs [52]. Patients with smoking habits are reported to develop resistance towards TKIs in both WT-EGFR and TKIssensitive EGFR mutants $[6,8]$. There are limited reports which explain the mechanisms associated with acquired resistance to TKIs upon acute exposure of cigarette smoke $[8,25]$. Filosto et al., have shown that acute exposure 
Figure 5
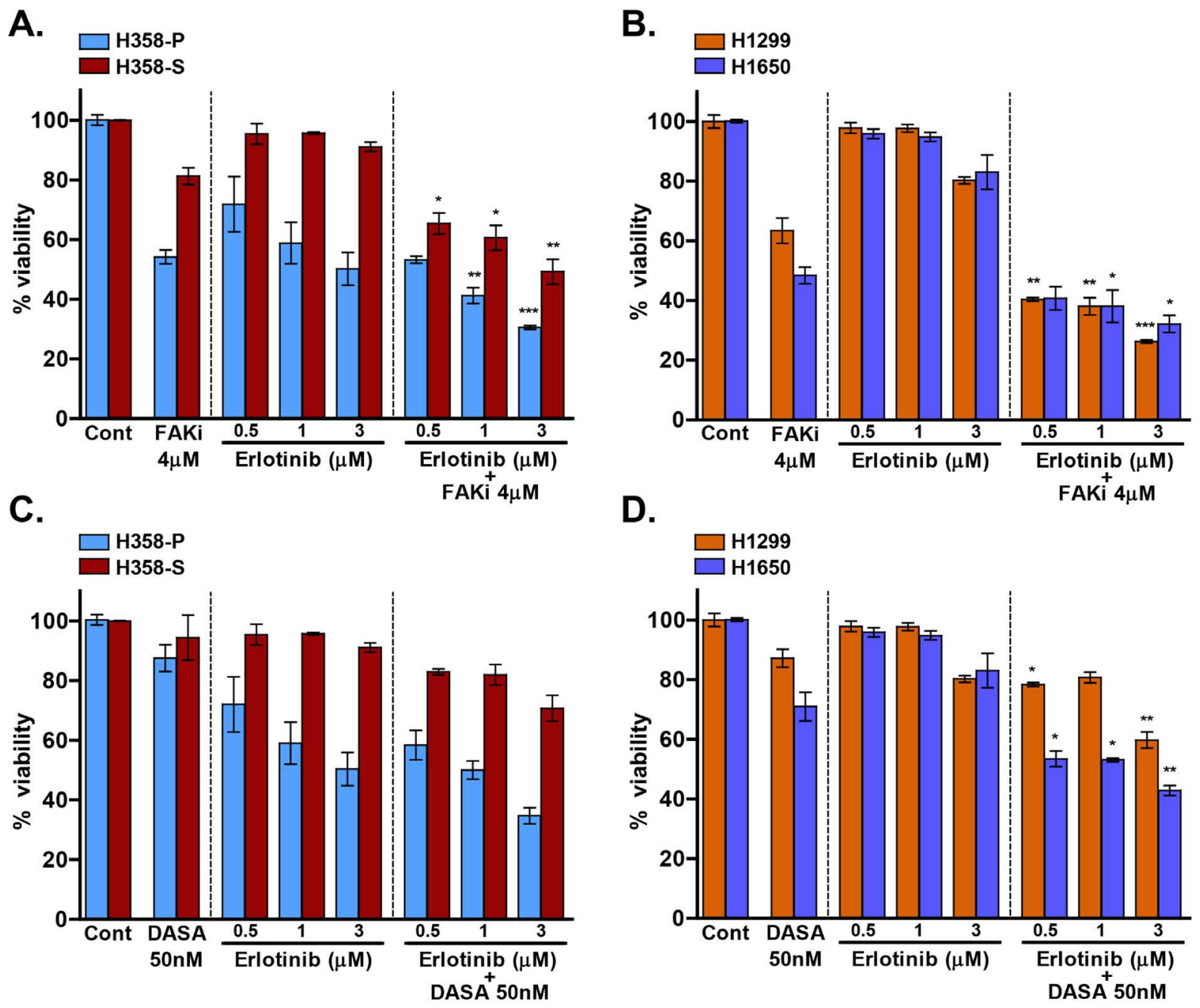

Figure 5: Targeting FAK overcomes erlotinib resistance in lung cancer cells. H358-S cells were treated with FAK inhibitor (FAKi) PF 562271 (A) or dasatinib (DASA) (C) alone or in combination with varying concentrations of erlotinib $(0.5 \mu \mathrm{M}, 1 \mu \mathrm{M}$ and 3 $\mu \mathrm{M})$. NSCLC cells, H1299 and H1650 were treated with PF 562271 (B) or with dasatinib (D) alone or in combination with the indicated concentrations of erlotinib. Cell viability was assessed using MTT assay. The data is presented as mean of \% viability \pm SEM as compared to DMSO-treated cells which served as control. The significance of combination therapies was assessed relative to most effective single agent treatment $(* \mathrm{p}<0.05, * * \mathrm{p}<0.01, * * * \mathrm{p}<0.001)$. 
Figure 6

A



C

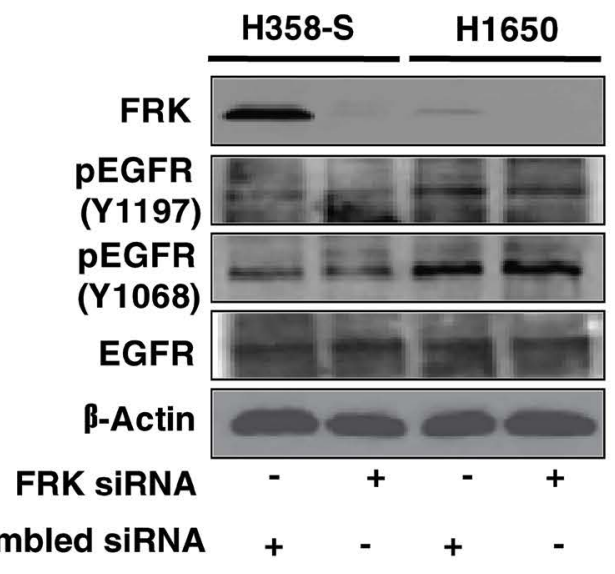

B

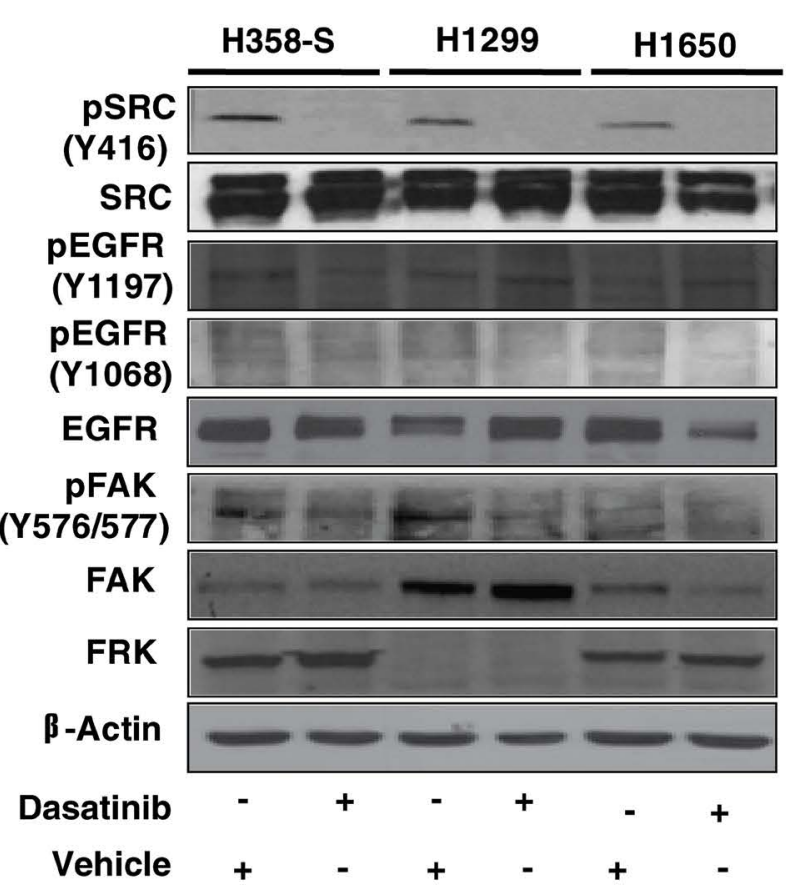

Figure 6: Western blot analysis depicting phosphorylation status of EGFR upon FAK and SRC inhibition in H358-S and in a panel of smoker-derived cell lines (H1299 and H1650). (A) The relative phosphorylation levels of in FAK (Y 576/577), EGFR (Y1197, Y1068) and FRK expression in H358-S, H1299 and H1650 cells treated either with DMSO (vehicle control) or dasatinib $(50 \mathrm{nM})$. (B) The relative expression of phosphorylated SRC (Y416), FAK (Y 576/577), EGFR (Y1197, Y1068) and FRK expression in H358-S, H1299 and H1650 cells treated either with DMSO (vehicle control) and PF 562271 (4 $\mu \mathrm{M})$. (C) H358-S and H1650 were transfected using scrambled or FRK siRNA and western blot analysis was performed for the indicated proteins. $\beta$-actin served as a loading control under all conditions. 
to cigarette smoke leads to the activation of SRC which in turn binds to EGFR and induce conformation change in ATP binding site of receptor [8]. Erlotinib is known to reversibly bind to the ATP binding site which interrupts further signaling cascade [53]. Along with SRC, CYP1A1 and Acetylcholine receptor (nAChR) were also suggested as potential targets to overcome smoking/ nicotinebased acquired resistance towards TKIs [54, 55]. Long term exposure to cigarette smoke is known to induce carboplatin resistance in NSCLC through down-regulation of SMAD family member 3 (SMAD3) [56]. In this study, using an in vitro cellular model that mimics long term cigarette smoking in NSCLC, we demonstrate that chronic exposure to cigarette smoke renders resistance to erlotinib.

To systematically characterize the signaling pathways leading to erlotinib resistance due to cigarette smoke exposure, we studied the phosphoproteomic alterations in H358-S and H358-P cells. In our data, we identified aberrant phosphorylation of receptor tyrosine kinases EGFR (Y1197), EPHA1 (Y781) and non-receptor tyrosine kinases including FAK (Y576/577) and FRK (Y46) in H358-S cells. EPHA2 expression is reported to be up-regulated in NSCLC, specifically in smokers [30] and has been shown to regulate acquired resistance towards TKIs [57]. A recent study using multiple reaction monitoring (MRM) based proteomics has shown increased phosphorylation of FAK1 amongst other proteins in erlotinib-resistant cells [58]. Other molecules which were found to be hyperphosphorylated in H358-S cells includes MAPK14, MAPK3, PXN, WASL, CTTN, CAV1 and TLN1, many of which are known to play a key role in SRC and FAK signaling. PXN is the known substrate of FAK [59] and plays critical role in tumorigenesis by regulating cytoskeleton arrangement by connecting integrins to FAK [60]. Studies indicate that MAPK3, CTTN and PXN regulate chemo or TKIs- based targeted therapy in cancer. TLN1 is known to activate integrins which in turn prevent cells from anoikis and promote metastasis via AKT pathway [61]. CTTN is a known substrate of $\mathrm{SRC}$ and is reported to induce gefitinib resistance in head and neck squamous cell carcinoma (HNSCC) [61]. FRK (related to Src family of kinases) is known to be aberrantly phosphorylated in NSCLC and there are reports which indicate its dual role as tumor suppressor or promoter depending on cell type [35]. Hyperphosphorylation at MAPK3 is reported to induce cisplatin resistance in lung cancer cells [62]. Yoshida et al., have reported activation of Src-family kinase network and SRC signaling was shown to work independent of EGFR in TKI-resistant NSCLC cells [63]. Several other studies have shown that smoke-induced EMT contributed to erlotinib resistance [20, 64, 65]. However, we did not find mesenchymal switch upon chronic exposure to cigarette smoke in our cell line model.

FAK is upregulated and differentially phosphorylated in multiple cancers including breast cancer and NSCLC [66-68]. We identified hyperphosphorylation of FAK at Y576/577 upon chronic exposure to cigarette smoke in lung cancer cells. Emerging studies have shown FAK as potential cancer target in multiple cancer types [69-71] and phase I/II clinical trial outcomes of FAK inhibitors are awaited [72]. A recent study reported higher efficacy and synergistic effects of FAK inhibitor when used in combination with erlotinib using in-vitro and in-vivo experiments [48]. The SRC-3Delta4, a SRC3 splicing isoform is known to mediate the interaction of FAK with EGFR in mammals [73]. FAK is reported to negatively regulate RTK-MAPK signaling by reducing the recycling of EGFR on plasma membrane [74]. The internalized receptor is reported to retain phosphorylation at Y1197 and localize in perinuclear region and nucleus upon oxidative stress [27] and radiation insult [26]. Studies have shown that phosphorylation of EGFR at its activation site Y1068 is a predictive maker to select TKIs responsive patient in NSCLC [32]. The same activation site is also reported to regulate internalization of receptor [75]. Erlotinib resistant cells have shown reduced activity of EGFR in multiple cell lines including NSCLC cells [18]. Interestingly, in our data H358-S and smoker derived NSCLC cells had decreased phosphorylation of EGFR at Y1068 and increased phosphorylation at Y1197 which is previously reported as site for internalization of receptor. Supporting our cell line observations, analysis of the signaling pathway activation in a large cohort of NSCLC tumors from TCGA database predicted that FAK signaling and EGFR internalization pathway were significantly elevated in tumors derived from the smoking patients, further supporting the role of cigarette smoke induced dysregulation of FAK signaling in lung tumorigenesis and resistance to EGFR targeted therapies.

Subsequently, our data shows that FAK inhibition using PF-562271 reinstates EGFR phosphorylation at Y1068 with subsequent reduction in phosphorylation at Y1197 and renders the cells sensitive to erlotinib. SRC is known to phosphorylate FAK at Y576/577 residue and, reports have suggested the use of dasatinib in combination therapy with TKIs, in NSCLC especially in smokers [8]. Here we report that, SRC inhibition using dasatinib was unable to restore the dependency of the cells to EGFR signaling. Our study reveals that FAK inhibition led to significant reduction in the expression of FRK in H358-S and NSCLC cells, whereas FRK expression remains unchanged upon dasatinib treatment suggesting that FRK might work downstream of FAK. Our study suggests that activation of FAK independent of SRC is sufficient to confer erlotinib resistance in NSCLC specifically in smokers.

Taken together, our data shows that cigarette smokeinduced activation of FAK signaling results in altered EGFR activity, leading to erlotinib resistance in NSCLC. 
In summary, our findings suggest that combination therapy targeting FAK and EGFR could prove to be an effective approach to treat NSCLC, in smoker population where only anti-EGFR therapy has shown limited success.

\section{MATERIALS AND METHODS}

\section{Cell culture and SILAC labelling}

Human lung cancer cell lines H358, H1299 and H1650 were obtained from American Type Culture Collection (ATCC, Manassas, VA). H358 cells were cultured in DMEM supplemented with $10 \%$ fetal bovine serum and $1 \%$ penicillin/streptomycin mixture. H1299 and H1650 were maintained in RPMI supplemented with $10 \%$ fetal bovine serum (Clontech, Mountain View, CA) and $1 \%$ penicillin/streptomycin mixture. All cells were grown in a humidified incubator maintained at $37 \mathrm{oC}$ and $5 \% \mathrm{CO}$. $\mathrm{H} 358$ cells were adapted and chronically treated with cigarette smoke condensate (CSC) as described in our previous study [15]. Briefly, the cells were exposed to CSC $(0.1 \%)$ for 12 months in a smoke dedicated incubator. Untreated or control cells were cultured in regular incubator. Untreated and smoke treated/exposed cells were designated as $\mathrm{H} 358-\mathrm{P}$ and $\mathrm{H} 358-\mathrm{S}$, respectively. $\mathrm{H} 358-\mathrm{P}$ cells were then adapted to ${ }^{13} \mathrm{C}_{6}$-lysine and ${ }^{13} \mathrm{C}_{6}$ arginine enriched SILAC media while H358-S cells were maintained in normal media.

\section{Trypsin digestion and Sep-Pak cleaning}

H358-P and H358-S were washed with ice cold 1X phosphate buffer saline after 12 hour of serum starvation. The cells were harvested and lysed in urea lysis buffer (20 mM HEPES $\mathrm{pH}$ 8.0, $9 \mathrm{M}$ urea, $1 \mathrm{mM}$ sodium orthovanadate, $2.5 \mathrm{mM}$ sodium pyrophosphate, $1 \mathrm{mM}$ phosphoglycerophosphate). Protein estimation was carried out using BCA (Pierce, Waltham, MA). Equal amount of protein from both conditions was pooled and subjected to reduction and alkylation using dithiothreitol $(5 \mathrm{mM})$ and iodoacetamide $(10 \mathrm{mM})$, respectively. Further, the lysate was diluted with HEPES buffer $(20 \mathrm{mM})$ to reduce the concentration of urea below $2 \mathrm{M}$ and kept for overnight digestion at $37^{\circ} \mathrm{C}$ using trypsin (Worthington Biochemical Corp, Lakewood, NJ). Sep-Pak C18 column (Waters, Cat\#WAT051910) was used to clean the peptide digest, which was further lyophilized and stored at $-80^{\circ} \mathrm{C}$.

\section{Immunoaffinity enrichment of tyrosine phosphopeptides}

Enrichment of tyrosine-containing peptides was done according to protocol described earlier $[13,76]$.
Briefly, lyophilized peptides were resuspended in 1.4 $\mathrm{ml}$ of IAP buffer (50 mM MOPS pH 7.2, $50 \mathrm{mM} \mathrm{NaCl}$, $10 \mathrm{mM}$ sodium phosphate) and $1 \mathrm{M}$ Tris Base was used adjusted $\mathrm{pH}$ at 7.2. P-Tyr-1000 beads (Cell Signaling Technology, Danvers, MA) were washed with IAP buffer at $4^{\circ} \mathrm{C}$. Peptides were incubated for 20 minutes with P-Tyr-1000. After washing beads with ice cold IAP buffer (thrice) and ice cold water (twice), peptides were eluted using trifluoroacetic acid (TFA) $(0.15 \%)$. Eluted peptides were concentrated by vacuum centrifugation and desalted using C18 StageTips prior to mass spectrometry analysis.

\section{LC-MS/MS and data analysis}

The enriched phosphotyrosine-containing peptides were analyzed on LTQ-Orbitrap Velos mass spectrometer (Thermo Electron, Bremen, Germany) interfaced with Easy-nLC II nanoflow liquid chromatography system (Thermo Scientific, Odense, Southern Denmark). The peptide digest was reconstituted in $0.1 \%$ formic acid and loaded on trap column $(75 \mu \mathrm{m} \times 2 \mathrm{~cm})$ packed with Magic $\mathrm{C}_{18}$ AQ (Michrom Bioresources, Inc., Auburn, CA, USA) $(5 \mu \mathrm{m}$ particle size, pore size $100 \AA)$. Peptides were separated on an analytical column $(75 \mu \mathrm{m} \times 15 \mathrm{~cm})$ with a linear gradient of ACN from 5 to $60 \%$ maintained at a flow rate of $350 \mathrm{nl} / \mathrm{min}$ in a 120 minutes run. MS and MS/MS analysis in Orbitrap mass analyzer was carried out at mass resolution of 60,000 and 15,000 at $\mathrm{m} / \mathrm{z}$ of 400 (scan range: $350-1700 \mathrm{~m} / \mathrm{z}$ ). HCD fragmentations of 15 most abundant ions were subjected to MS/MS analysis (isolation width of $1.90 \mathrm{~m} / \mathrm{z}$ and normalized collision energy of $39 \%$ ).

Mass spectrometry data was searched against a Human RefSeq database (RefSeq 59) which was appended with frequently observed contaminants using MASCOT (v 2.2) and SEQUEST search algorithms through the Proteome Discoverer platform (v1.4, Thermo Scientific, Bremen, Germany). For both algorithms, the search parameter included maximum of 2 missed cleavage, fixed modification of carbamidomethylation at cysteine and dynamic modification included oxidation of methionine, phosphorylation at serine, threonine and tyrosine (+79.966 Da) and SILAC labels 13C6-Lysine; 13C6Arginine $(+6.02013 \mathrm{Da})$. The precursor mass error tolerance and fragment ion mass error tolerance was set to $20 \mathrm{ppm}$ and $0.1 \mathrm{Da}$, respectively. In addition, decoy database search was carried out to calculate false discovery rate (FDR). FDR of $1 \%$ was considered for peptide identification. The PhosphoRS node (Version 3.0) in the Proteome Discoverer was used to calculate the phosphorylation probability at Y residue [77] and peptides greater than $75 \%$ site localization probability was considered for further analysis. 


\section{LC-MS/MS data availability}

The raw data has been submitted to ProteomeXchange Consortium (http://www. proteomecentral.proteomexchange.org) via the PRIDE public data repository [78] and can be accessed using the data identifier - PXD006705.

\section{Western blotting}

The H358-P and H358-S cells were lysed using modified RIPA lysis buffer (Merck Millipore, Billerica, MA,) containing protease inhibitors (Roche, Indianapolis, IN,) and phosphatase inhibitors (Thermo Scientific, Bremen, Germany). Western blot analysis was performed as described previously using $30 \mu \mathrm{g}$ protein lysates [79, 80]. Briefly, lysate were resolved and transferred on nitrocellulose membranes, which was further hybridized with primary antibodies and developed using Luminol reagent (Santa Cruz Biotechnology, Dallas, TX,). AntiEGFR, phospho-EGFR (Y1068 and Y1197), anti-FAK, phospho-FAK (Y576/577), anti-SRC, and phospho-SRC (Y416) antibodies were obtained from Cell Signaling Technology (Cell Signaling Technology, Beverly, MA). Anti-FRK antibody was obtained from Santa Cruz Biotechnology. Beta-actin antibody was obtained from Sigma (St. Louis, MO). The FAK inhibitor PF-562271 was purchased from Santa Cruz Biotechnology (Dallas, TX). Erlotinib and Dasatinib were purchased from Selleckchem (Houston, TX). DMSO was used as vehicle in all experiments.

\section{siRNA transfection}

The H358-S, H1299 and H1650 cells were transfected with ON-TARGETplus SMARTpool control siRNA and FRK siRNA (Dharmacon, Lafayette, CO) using RNAiMAX (Invitrogen, Grand Island, NY) following manufacturer's instructions. Transfection was carried out according to previously described protocol [79]. The efficiency of transfection was determined by western blot analysis. For MTT assays, drug treatment was done 24 hours post-siRNA transfection. For western blot analysis, cells were harvested 48 hours post-transfection. Cells were subjected to invasion assays 24 hours posttransfection and stained after 48 hours.

\section{Invasion assays}

The invasion assays were performed similar to previously described protocol using a transwell system (BD Biosciences, San Jose, CA) with Matrigel-coated filters [80, 81]. Each experiment was performed in triplicate and the experiments were repeated three times.

\section{Cell viability assays}

Cells were seeded in 96 well plates at density of 5000 cells/well and incubated overnight. To assess the effect of erlotinib or PF-562271 on cell viability, the cells were treated at different concentration of drug in media supplemented with 5\% FBS and incubated for 72 hours. Cell viability was determined using MTT reagent and absorbance at $570 \mathrm{~nm}$ and $650 \mathrm{~nm}$ was taken using Multiscan plate reader. For combination treatment of erlotinib and PF-562271 or erlotinib and dasatinib, the cells were treated with PF-562271 or dasatinib for 24 hoursfollowed by erlotinib treatment. The MTT reading was taken post 72 hours of erlotinib treatment. All treatments was done in triplicates and each experiment was repeated thrice. The mean value of cell viability from replicates was taken to express the percentage of viability relative to DMSO as control treatment.

\section{Phosphotyrosine based pathway analysis}

The pathway analysis of the differentially expressed proteins was carried out using QIAGEN's Ingenuity ${ }^{\circledR}$ Pathway Analysis (IPA ${ }^{\circledR}$, QIAGEN Redwood City, www. qiagen.com/ingenuity) and STITCH tool (version 5.0) [82]. We had considered top 5 enriched pathways for both the tools.

\section{Expression data processing}

RNA-Seq data was retrieved from TCGA database. Data preprocessing and normalization steps were performed in $\mathrm{R}$ version 3.1.0 using DEseq package from Bioconductor. To adjust for the possible batch and processing effect we have employed XPN algorithm (R package, CONOR), as previously described [83]. The resulting matrix contained mRNA expression information for over $20 \mathrm{~K}$ genes across all analyzed samples. Normalized gene expression data were loaded into iPANDA [16, 17]. The software enables calculation of the Pathway Activation Score (PAS) for each of the pathways analyzed, a value which serves as a quantitative measure of differential pathway activation. A collection of intracellular signaling pathways strongly implicated with various solid malignancies was obtained from the NCI Pathway Interaction Database, and used for the computational algorithm as described previously $[16,17]$. Calculated PAS values for pathways associated with FAK signaling are shown.

\section{In vivo studies}

H358-P $\left(2 \times 10^{6}\right)$ and H358-S cells $\left(2 \times 10^{6}\right)$ were injected subcutaneously in flanks of 6-week- old NOD- 
SCID male mice. Two mice for each cell line were used for study. Mice were housed in pathogen free conditions and experiments were conducted according to the institutional ethical guidelines at the experimental animal facility of Indian Institute of Sciences, Bangalore, India. The measurement of tumor size was done using caliper every 3 and tumor volume was calculated using following formula - $(\pi / 6(d 1 x d 2) 3 / 2)[84]$.

\section{Statistical analysis}

All statistical analysis was performed using Graphpad Prism software (version 6.0) (2-tailed t-test) and data with $\mathrm{p}<0.05$ were considered statistically significant.

\section{Abbreviations}

BCA: Bicinchoninic acid assay

CSC: Cigarette smoke condensate

EGFR: Epidermal growth factor receptor

FAK: Focal adhesion kinase

IAP: Immunoaffinity purification

NSCLC: Non small cell lung carcinoma

SILAC: Stable isotope labeling by amino acids in cell culture

\section{Author contributions}

$\mathrm{AC}$ and $\mathrm{HG}$ conceived and supervised the study; AC, HSS and RR designed experiments; HSS, RR, AR, NB, VNP, NS, VN and TS performed experiments; AR, NAS and HSS carried out mass spectrometry analysis; JA, EI, AZ, IVO, AVA, AHP and DG carried out bioinformatics analysis; HSS and RR wrote the manuscript; TSKP, XC, PPM, AR, DS, EI, AZ, IVO, DG, AVA and AP provided critical inputs and revised the manuscript. AC, EI, AZ, IVO, AVA, DG and HG made manuscript revisions

\section{ACKNOWLEDGEMENTS}

We thank the Department of Biotechnology (DBT), Government of India for research support to the Institute of Bioinformatics (IOB), Bangalore. This work was supported by Department of Science and Technology (DST) grants (SERC/LS-439/2011 and SR/ $\mathrm{SO} / \mathrm{HS} / 0208 / 2013)$. IOB is supported by DBT Program Support on Neuroproteomics and infrastructure for proteomic data analysis (BT/01/COE/08/05). This work was supported by NCI's Clinical Proteomic Tumor Analysis Consortium initiative (U24CA160036), FAMRI-funded 072017_YCSA and ALCF-IASLC. RR is a recipient of Startup research scheme from DST. JA is a recipient of Senior Research Fellowship and NB is a recipient of Junior Research Fellowship from Council of Scientific and Industrial Research (CSIR), Government of India. We thank Dr. S. K. Shankar and Dr. Anita Mahadevan (NIMHANS) for providing access to the microscopy imaging facility.

\section{CONFLICTS OF INTEREST}

The authors declare that they have no potential conflict of interest.

\section{REFERENCES}

1. Herbst RS, Heymach JV, Lippman SM. Lung cancer. N Engl J Med. 2008; 359:1367-80.

2. Wu P, Nielsen TE, Clausen MH. FDA-approved smallmolecule kinase inhibitors. Trends Pharmacol Sci. 2015; 36:422-39.

3. Pao W, Miller VA. Epidermal growth factor receptor mutations, small-molecule kinase inhibitors, and non-smallcell lung cancer: current knowledge and future directions. J Clin Oncol. 2005; 23:2556-68.

4. Suda K, Mizuuchi H, Maehara Y, Mitsudomi T. Acquired resistance mechanisms to tyrosine kinase inhibitors in lung cancer with activating epidermal growth factor receptor mutation - diversity, ductility, and destiny. Cancer Metastasis Rev. 2012; 31:807-14.

5. Ahsan A. Mechanisms of Resistance to EGFR Tyrosine Kinase Inhibitors and Therapeutic Approaches: an Update. Adv Exp Med Biol. 2016; 893:137-53.

6. Zhang Y, Kang S, Fang W, Hong S, Liang W, Yan Y, Qin T, Tang Y, Sheng J, Zhang L. Impact of smoking status on EGFR-TKI efficacy for advanced non-small-cell lung cancer in EGFR mutants: a meta-analysis. Clin Lung Cancer. 2015; 16: 144-51 e1.

7. Hasegawa Y, Ando M, Maemondo M, Yamamoto S, Isa S, Saka H, Kubo A, Kawaguchi T, Takada M, Rosell R, Kurata $\mathrm{T}, \mathrm{Ou} \mathrm{SH}$. The role of smoking status on the progressionfree survival of non-small cell lung cancer patients harboring activating epidermal growth factor receptor (EGFR) mutations receiving first-line EGFR tyrosine kinase inhibitor versus platinum doublet chemotherapy: a metaanalysis of prospective randomized trials. Oncologist. 2015; 20:307-15.

8. Filosto S, Baston DS, Chung S, Becker CR, Goldkorn T. Src mediates cigarette smoke-induced resistance to tyrosine kinase inhibitors in NSCLC cells. Mol Cancer Ther. 2013; 12:1579-90.

9. Zhao H, Albino AP, Jorgensen E, Traganos F, Darzynkiewicz Z. DNA damage response induced by tobacco smoke in normal human bronchial epithelial and A549 pulmonary adenocarcinoma cells assessed by laser scanning cytometry. Cytometry A. 2009; 75:840-47.

10. Albino AP, Huang X, Jorgensen E, Yang J, Gietl D, Traganos F, Darzynkiewicz Z. Induction of H2AX 
phosphorylation in pulmonary cells by tobacco smoke: a new assay for carcinogens. Cell Cycle. 2004; 3:1062-68.

11. Mossina A, Lukas C, Merl-Pham J, Uhl FE, Mutze K, Schamberger A, Staab-Weijnitz C, Jia J, Yildirim AO, Königshoff M, Hauck SM, Eickelberg O, Meiners S. Cigarette smoke alters the secretome of lung epithelial cells. Proteomics. 2017; 17:1600243.

12. Radhakrishnan A, Nanjappa V, Raja R, Sathe G, Puttamallesh VN, Jain AP, Pinto SM, Balaji SA, Chavan S, Sahasrabuddhe NA, Mathur PP, Kumar MM, Prasad TS, et al. A dual specificity kinase, DYRK1A, as a potential therapeutic target for head and neck squamous cell carcinoma. Sci Rep. 2016; 6:36132.

13. Sathe G, Pinto SM, Syed N, Nanjappa V, Solanki HS, Renuse S, Chavan S, Khan AA, Patil AH, Nirujogi RS, Nair B, Mathur PP, Prasad TS, et al. Phosphotyrosine profiling of curcumin-induced signaling. Clin Proteomics. 2016; 13:13.

14. Wu X, Zahari MS, Renuse S, Nirujogi RS, Kim MS, Manda SS, Stearns V, Gabrielson E, Sukumar S, Pandey A. Phosphoproteomic Analysis Identifies Focal Adhesion Kinase 2 (FAK2) as a Potential Therapeutic Target for Tamoxifen Resistance in Breast Cancer. Mol Cell Proteomics. 2015; 14:2887-900.

15. Raja R, Sahasrabuddhe NA, Radhakrishnan A, Syed N, Solanki HS, Puttamallesh VN, Balaji SA, Nanjappa V, Datta KK, Babu N, Renuse S, Patil AH, Izumchenko E, et al. Chronic exposure to cigarette smoke leads to activation of p21 (RAC1)-activated kinase 6 (PAK6) in non-small cell lung cancer cells. Oncotarget. 2016; 7:61229-45. https:// doi.org/10.18632/oncotarget.11310.

16. Ozerov IV, Lezhnina KV, Izumchenko E, Artemov AV, Medintsev S, Vanhaelen Q, Aliper A, Vijg J, Osipov AN, Labat I, West MD, Buzdin A, Cantor CR, et al. In silico Pathway Activation Network Decomposition Analysis (iPANDA) as a method for biomarker development. Nat Commun. 2016; 7:13427.

17. Makarev E, Schubert AD, Kanherkar RR, London N, Teka M, Ozerov I, Lezhnina K, Bedi A, Ravi R, Mehra R, Hoque MO, Sloma I, Gaykalova DA, et al. In silico analysis of pathways activation landscape in oral squamous cell carcinoma and oral leukoplakia. Cell Death Discov. 2017; 3: 17022 .

18. Chang X, Izumchenko E, Solis LM, Kim MS, Chatterjee A, Ling S, Monitto CL, Harari PM, Hidalgo M, Goodman SN, Wistuba II, Bedi A, Sidransky D. The relative expression of Mig6 and EGFR is associated with resistance to EGFR kinase inhibitors. PLoS One. 2013; 8:e68966.

19. Zhang H, Liu H, Borok Z, Davies KJ, Ursini F, Forman HJ. Cigarette smoke extract stimulates epithelial-mesenchymal transition through Src activation. Free Radic Biol Med. 2012; 52:1437-42.

20. Li D, Zhang L, Zhou J, Chen H. Cigarette smoke extract exposure induces EGFR-TKI resistance in EGFR-mutated NSCLC via mediating Src activation and EMT. Lung Cancer. 2016; 93:35-42.
21. Tang Y, Lv P, Sun Z, Han L, Zhou W. 14-3-3 $\beta$ Promotes Migration and Invasion of Human Hepatocellular Carcinoma Cells by Modulating Expression of MMP2 and MMP9 through PI3K/Akt/NF-kB Pathway. PLoS One. 2016; 11:e0146070.

22. Gao J, Zhu Y, Nilsson M, Sundfeldt K. TGF- $\beta$ isoforms induce EMT independent migration of ovarian cancer cells. Cancer Cell Int. 2014; 14:72.

23. Waller LL, Miller AA, Petty WJ. Using erlotinib to treat patients with non-small cell lung cancer who continue to smoke. Lung Cancer. 2010; 67:12-16.

24. Lynch TJ, Bell DW, Sordella R, Gurubhagavatula S, Okimoto RA, Brannigan BW, Harris PL, Haserlat SM, Supko JG, Haluska FG, Louis DN, Christiani DC, Settleman $\mathrm{J}$, Haber DA. Activating mutations in the epidermal growth factor receptor underlying responsiveness of non-small-cell lung cancer to gefitinib. N Engl J Med. 2004; 350:2129-39.

25. Filosto S, Becker CR, Goldkorn T. Cigarette smoke induces aberrant EGF receptor activation that mediates lung cancer development and resistance to tyrosine kinase inhibitors. Mol Cancer Ther. 2012; 11:795-804.

26. Dittmann K, Mayer C, Kehlbach R, Rodemann HP. Radiation-induced caveolin-1 associated EGFR internalization is linked with nuclear EGFR transport and activation of DNA-PK. Mol Cancer. 2008; 7:69.

27. Khan EM, Heidinger JM, Levy M, Lisanti MP, Ravid T, Goldkorn T. Epidermal growth factor receptor exposed to oxidative stress undergoes Src- and caveolin-1-dependent perinuclear trafficking. J Biol Chem. 2006; 281:14486-93.

28. Xi HQ, Wu XS, Wei B, Chen L. Eph receptors and ephrins as targets for cancer therapy. J Cell Mol Med. 2012; 16:2894-909.

29. Ishikawa M, Miyahara R, Sonobe M, Horiuchi M, Mennju T, Nakayama E, Kobayashi M, Kikuchi R, Kitamura J, Imamura N, Huang CL, Date H. Higher expression of EphA2 and ephrin-A1 is related to favorable clinicopathological features in pathological stage I nonsmall cell lung carcinoma. Lung Cancer. 2012; 76:431-38.

30. Brannan JM, Dong W, Prudkin L, Behrens C, Lotan R, Bekele BN, Wistuba I, Johnson FM. Expression of the receptor tyrosine kinase EphA2 is increased in smokers and predicts poor survival in non-small cell lung cancer. Clin Cancer Res. 2009; 15:4423-30.

31. Sette G, Salvati V, Mottolese M, Visca P, Gallo E, Fecchi K, Pilozzi E, Duranti E, Policicchio E, Tartaglia M, Milella M, De Maria R, Eramo A. Tyr1068-phosphorylated epidermal growth factor receptor (EGFR) predicts cancer stem cell targeting by erlotinib in preclinical models of wild-type EGFR lung cancer. Cell Death Dis. 2015; 6:e1850.

32. Harsha HC, Jimeno A, Molina H, Mihalas AB, Goggins MG, Hruban RH, Schulick RD, Kamath U, Maitra A, Hidalgo M, Pandey A. Activated epidermal growth factor receptor as a novel target in pancreatic cancer therapy. $\mathrm{J}$ Proteome Res. 2008; 7:4651-58. 
33. Fang X, Liu X, Yao L, Chen C, Lin J, Ni P, Zheng X, Fan Q. New insights into FAK phosphorylation based on a FAT domain-defective mutation. PLoS One. 2014; 9:e107134.

34. Bolós V, Gasent JM, López-Tarruella S, Grande E. The dual kinase complex FAK-Src as a promising therapeutic target in cancer. Onco Targets Ther. 2010; 3:83-97.

35. Goel RK, Lukong KE. Understanding the cellular roles of Fyn-related kinase (FRK): implications in cancer biology. Cancer Metastasis Rev. 2016; 35:179-99.

36. Rikova K, Guo A, Zeng Q, Possemato A, Yu J, Haack H, Nardone J, Lee K, Reeves C, Li Y, Hu Y, Tan Z, Stokes M, et al. Global survey of phosphotyrosine signaling identifies oncogenic kinases in lung cancer. Cell. 2007; 131:1190-203.

37. Mitra SK, Hanson DA, Schlaepfer DD. Focal adhesion kinase: in command and control of cell motility. Nat Rev Mol Cell Biol. 2005; 6:56-68.

38. Canel M, Serrels A, Frame MC, Brunton VG. E-cadherinintegrin crosstalk in cancer invasion and metastasis. J Cell Sci. 2013; 126:393-401.

39. Avizienyte E, Wyke AW, Jones RJ, McLean GW, Westhoff MA, Brunton VG, Frame MC. Src-induced de-regulation of E-cadherin in colon cancer cells requires integrin signalling. Nat Cell Biol. 2002; 4:632-38.

40. Chen HC, Appeddu PA, Isoda H, Guan JL. Phosphorylation of tyrosine 397 in focal adhesion kinase is required for binding phosphatidylinositol 3-kinase. J Biol Chem. 1996; 271:26329-34.

41. Xia H, Nho RS, Kahm J, Kleidon J, Henke CA. Focal adhesion kinase is upstream of phosphatidylinositol 3-kinase/ Akt in regulating fibroblast survival in response to contraction of type I collagen matrices via a beta 1 integrin viability signaling pathway. J Biol Chem. 2004; 279:33024-34.

42. Sulzmaier FJ, Jean C, Schlaepfer DD. FAK in cancer: mechanistic findings and clinical applications. Nat Rev Cancer. 2014; 14:598-610.

43. Sorkin A, Waters C, Overholser KA, Carpenter G. Multiple autophosphorylation site mutations of the epidermal growth factor receptor. Analysis of kinase activity and endocytosis. J Biol Chem. 1991; 266:8355-62.

44. Helin K, Beguinot L. Internalization and down-regulation of the human epidermal growth factor receptor are regulated by the carboxyl-terminal tyrosines. J Biol Chem. 1991; 266:8363-68.

45. Zhang G, Fang B, Liu RZ, Lin H, Kinose F, Bai Y, Oguz U, Remily-Wood ER, Li J, Altiok S, Eschrich S, Koomen J, Haura EB. Mass spectrometry mapping of epidermal growth factor receptor phosphorylation related to oncogenic mutations and tyrosine kinase inhibitor sensitivity. J Proteome Res. 2011; 10:305-19.

46. Brand TM, Dunn EF, Iida M, Myers RA, Kostopoulos KT, Li C, Peet CR, Wheeler DL. Erlotinib is a viable treatment for tumors with acquired resistance to cetuximab. Cancer Biol Ther. 2011; 12:436-46.

47. Wang F, Wang S, Wang Z, Duan J, An T, Zhao J, Bai
$\mathrm{H}$, Wang $\mathrm{J}$, and Key Laboratory of Carcinogenesis and Translational Research (Ministry of Education). Phosphorylated EGFR expression may predict outcome of EGFR-TKIs therapy for the advanced NSCLC patients with wild-type EGFR. J Exp Clin Cancer Res. 2012; 31:65.

48. Howe GA, Xiao B, Zhao H, Al-Zahrani KN, Hasim MS, Villeneuve J, Sekhon HS, Goss GD, Sabourin LA, Dimitroulakos J, Addison CL. Focal Adhesion Kinase Inhibitors in Combination with Erlotinib Demonstrate Enhanced Anti-Tumor Activity in Non-Small Cell Lung Cancer. PLoS One. 2016; 11:e0150567.

49. Gold KA, Lee JJ, Harun N, Tang X, Price J, Kawedia JD, Tran HT, Erasmus JJ, Blumenschein GR, William WN, Wistuba II, Johnson FM. A phase I/II study combining erlotinib and dasatinib for non-small cell lung cancer. Oncologist. 2014; 19:1040-41.

50. Song L, Morris M, Bagui T, Lee FY, Jove R, Haura EB. Dasatinib (BMS-354825) selectively induces apoptosis in lung cancer cells dependent on epidermal growth factor receptor signaling for survival. Cancer Res. 2006; 66:5542-48.

51. Gridelli C, Rossi A, Carbone DP, Guarize J, Karachaliou N, Mok T, Petrella F, Spaggiari L, Rosell R. Non-small-cell lung cancer. Nat Rev Dis Primers. 2015; 1:15009.

52. Zhu CQ, da Cunha Santos G, Ding K, Sakurada A, Cutz JC, Liu N, Zhang T, Marrano P, Whitehead M, Squire JA, KamelReid S, Seymour L, Shepherd FA, Tsao MS, and National Cancer Institute of Canada Clinical Trials Group Study BR.21. Role of KRAS and EGFR as biomarkers of response to erlotinib in National Cancer Institute of Canada Clinical Trials Group Study BR.21. J Clin Oncol. 2008; 26:4268-75.

53. Raymond E, Faivre S, Armand JP. Epidermal growth factor receptor tyrosine kinase as a target for anticancer therapy. Drugs. 2000 (Suppl 1); 60:15-23.

54. Alfieri RR, Galetti M, Tramonti S, Andreoli R, Mozzoni P, Cavazzoni A, Bonelli M, Fumarola C, La Monica S, Galvani E, De Palma G, Mutti A, Mor M, et al. Metabolism of the EGFR tyrosin kinase inhibitor gefitinib by cytochrome P450 1A1 enzyme in EGFR-wild type non small cell lung cancer cell lines. Mol Cancer. 2011; 10:143.

55. Togashi Y, Hayashi H, Okamoto K, Fumita S, Terashima M, de Velasco MA, Sakai K, Fujita Y, Tomida S, Nakagawa K, Nishio K. Chronic nicotine exposure mediates resistance to EGFR-TKI in EGFR-mutated lung cancer via an EGFR signal. Lung Cancer. 2015; 88:16-23.

56. Samanta D, Kaufman J, Carbone DP, Datta PK. Long-term smoking mediated down-regulation of Smad3 induces resistance to carboplatin in non-small cell lung cancer. Neoplasia. 2012; 14:644-55.

57. Koch H, Busto ME, Kramer K, Médard G, Kuster B. Chemical Proteomics Uncovers EPHA2 as a Mechanism of Acquired Resistance to Small Molecule EGFR Kinase Inhibition. J Proteome Res. 2015; 14:2617-25.

58. Kim HJ, Lin D, Lee HJ, Li M, Liebler DC. Quantitative Profiling of Protein Tyrosine Kinases in Human Cancer Cell Lines by Multiplexed Parallel Reaction Monitoring Assays. 
Mol Cell Proteomics. 2016; 15:682-91.

59. Beinke C, Van Beuningen D, Cordes N. Ionizing radiation modules of the expression and tyrosine phosphorylation of the focal adhesion-associated proteins focal adhesion kinase (FAK) and its substrates p130cas and paxillin in A549 human lung carcinoma cells in vitro. Int J Radiat Biol. 2003; 79:721-31.

60. Kanteti R, Batra SK, Lennon FE, Salgia R. FAK and paxillin, two potential targets in pancreatic cancer. Oncotarget. 2016; 7:31586-601. https://doi.org/10.18632/ oncotarget. 8040

61. Desiniotis A, Kyprianou N. Significance of talin in cancer progression and metastasis. Int Rev Cell Mol Biol. 2011; 289:117-47.

62. Wang M, Liu ZM, Li XC, Yao YT, Yin ZX. Activation of ERK1/2 and Akt is associated with cisplatin resistance in human lung cancer cells. J Chemother. 2013; 25:162-69.

63. Yoshida T, Zhang G, Smith MA, Lopez AS, Bai Y, Li J, Fang B, Koomen J, Rawal B, Fisher KJ, Chen YA, Kitano M, Morita Y, et al. Tyrosine phosphoproteomics identifies both codrivers and cotargeting strategies for T790M-related EGFR-TKI resistance in non-small cell lung cancer. Clin Cancer Res. 2014; 20:4059-74.

64. Vu T, Jin L, Datta PK. Effect of Cigarette Smoking on Epithelial to Mesenchymal Transition (EMT) in Lung Cancer. J Clin Med. 2016; 5:E44.

65. Liu M, Zhou C, Zheng J. Cigarette smoking impairs the response of EGFR-TKIs therapy in lung adenocarcinoma patients by promoting EGFR signaling and epithelialmesenchymal transition. Am J Transl Res. 2015; 7:2026-35.

66. Wang B, Qi X, Li D, Feng M, Meng X, Fu S. Expression of pY397 FAK promotes the development of non-small cell lung cancer. Oncol Lett. 2016; 11:979-83.

67. Yoon H, Dehart JP, Murphy JM, Lim ST. Understanding the roles of FAK in cancer: inhibitors, genetic models, and new insights. J Histochem Cytochem. 2015; 63:114-28.

68. Kallergi G, Mavroudis D, Georgoulias V, Stournaras C. Phosphorylation of FAK, PI-3K, and impaired actin organization in CK-positive micrometastatic breast cancer cells. Mol Med. 2007; 13:79-88.

69. Pak JH, Bashir Q, Kim IK, Hong SJ, Maeng S, Bahk YY, Kim TS. Clonorchis sinensis excretory-secretory products promote the migration and invasion of cholangiocarcinoma cells by activating the integrin $\beta 4-\mathrm{FAK} / \mathrm{Src}$ signaling pathway. Mol Biochem Parasitol. 2017; 214:1-9.

70. Xu B, Lefringhouse J, Liu Z, West D, Baldwin LA, Ou C, Chen L, Napier D, Chaiswing L, Brewer LD, St Clair D, Thibault O, van Nagell JR, et al. Inhibition of the integrin/ FAK signaling axis and c-Myc synergistically disrupts ovarian cancer malignancy. Oncogenesis. 2017; 6:e295.

71. Yang L, Zhou Q, Chen X, Su L, Liu B, Zhang H. Activation of the FAK/PI3K pathway is crucial for AURKA-induced epithelial-mesenchymal transition in laryngeal cancer. Oncol Rep. 2016; 36:819-26.
72. Shanthi E, Krishna MH, Arunesh GM, Venkateswara Reddy K, Sooriya Kumar J, Viswanadhan VN. Focal adhesion kinase inhibitors in the treatment of metastatic cancer: a patent review. Expert Opin Ther Pat. 2014; 24: 1077-100.

73. Long W, Yi P, Amazit L, LaMarca HL, Ashcroft F, Kumar R, Mancini MA, Tsai SY, Tsai MJ, O’Malley BW. SRC3Delta4 mediates the interaction of EGFR with FAK to promote cell migration. Mol Cell. 2010; 37:321-32.

74. Macagno JP, Diaz Vera J, Yu Y, MacPherson I, Sandilands E, Palmer R, Norman JC, Frame M, Vidal M. FAK acts as a suppressor of RTK-MAP kinase signalling in Drosophila melanogaster epithelia and human cancer cells. PLoS Genet. 2014; 10:e1004262.

75. Sorkina T, Huang F, Beguinot L, Sorkin A. Effect of tyrosine kinase inhibitors on clathrin-coated pit recruitment and internalization of epidermal growth factor receptor. $\mathrm{J}$ Biol Chem. 2002; 277:27433-41.

76. Rush J, Moritz A, Lee KA, Guo A, Goss VL, Spek EJ, Zhang $\mathrm{H}$, Zha XM, Polakiewicz RD, Comb MJ. Immunoaffinity profiling of tyrosine phosphorylation in cancer cells. Nat Biotechnol. 2005; 23:94-101.

77. Taus T, Köcher T, Pichler P, Paschke C, Schmidt A, Henrich C, Mechtler K. Universal and confident phosphorylation site localization using phosphoRS. J Proteome Res. 2011; 10:5354-62.

78. Vizcaíno JA, Côté RG, Csordas A, Dianes JA, Fabregat A, Foster JM, Griss J, Alpi E, Birim M, Contell J, O'Kelly G, Schoenegger A, Ovelleiro D, et al. The PRoteomics IDEntifications (PRIDE) database and associated tools: status in 2013. Nucleic Acids Res. 2013; 41:D1063-69.

79. Chang X, Ravi R, Pham V, Bedi A, Chatterjee A, Sidransky D. Adenylate kinase 3 sensitizes cells to cigarette smoke condensate vapor induced cisplatin resistance. PLoS One. 2011; 6:e20806.

80. Subbannayya Y, Syed N, Barbhuiya MA, Raja R, Marimuthu A, Sahasrabuddhe N, Pinto SM, Manda SS, Renuse S, Manju HC, Zameer MA, Sharma J, Brait M, et al. Calcium calmodulin dependent kinase kinase 2 - a novel therapeutic target for gastric adenocarcinoma. Cancer Biol Ther. 2015; 16:336-45.

81. Behera R, Kumar V, Lohite K, Karnik S, Kundu GC. Activation of JAK2/STAT3 signaling by osteopontin promotes tumor growth in human breast cancer cells. Carcinogenesis. 2010; 31:192-200.

82. Szklarczyk D, Santos A, von Mering C, Jensen LJ, Bork $\mathrm{P}$, Kuhn M. STITCH 5: augmenting protein-chemical interaction networks with tissue and affinity data. Nucleic Acids Res. 2016; 44:D380-84.

83. Shabalin AA, Tjelmeland H, Fan C, Perou CM, Nobel AB. Merging two gene-expression studies via cross-platform normalization. Bioinformatics. 2008; 24:1154-60.

84. Raja R, Kale S, Thorat D, Soundararajan G, Lohite K, Mane A, Karnik S, Kundu GC. Hypoxia-driven osteopontin contributes to breast tumor growth through modulation of HIF1 $\alpha$-mediated VEGF-dependent angiogenesis. Oncogene. 2014; 33:2053-64. 